\title{
Analysis of the methylation status of the KCNQ10T and H19 genes in leukocyte DNA for the diagnosis and prognosis of Beckwith - Wiedemann syndrome
}

\author{
Véronique Gaston ${ }^{1}$, Yves Le Bouc ${ }^{1}$, Véronique Soupre ${ }^{2}$, Lydie Burglen ${ }^{3}$, Jeam Donadieu ${ }^{4}$, \\ Hubert Oro ${ }^{5}$, Georges Audry ${ }^{5}$, Marie-Paule Vazquez ${ }^{2}$ and Christine Gicquel*,1
}

${ }^{1}$ Laboratoire d'Explorations Fonctionnelles Endocriniennes, Hôpital Trousseau, AP-HP, Paris, France; ${ }^{2}$ Service de chirurgie maxillo-faciale, Hôpital Trousseau, AP-HP, Paris, France; ${ }^{3}$ Service de génétique médicale, Hôpital Trousseau, AP-HP, Paris, France; ${ }^{4}$ Service d'hémato-oncologie, Hôpital Trousseau, AP-HP, Paris, France; ${ }^{5}$ Service de chirurgie viscérale, Hôpital Trousseau, AP-HP, Paris, France

Beckwith - Wiedemann syndrome (BWS) is an overgrowth disorder involving developmental abnormalities, tissue and organ hyperplasia and an increased risk of embryonal tumours (most commonly Wilms tumour). This multigenic disorder is caused by dysregulation of the expression of imprinted genes in the $11 \mathrm{p} 15$ chromosomal region. Molecular diagnosis of BWS is currently difficult, mostly due to the large spectrum of genetic and epigenetic abnormalities. The other difficulty in managing BWS is the identification of patients at risk of tumour. An imprinted antisense transcript within KCNQ1, called KCNQ10T (also known as LIT1), was recently shown to be normally expressed from the paternal allele. A loss of imprinting of the KCNQ1OT gene, associated with the loss of maternal allele-specific methylation of the differentially methylated region KvDMR1 has been described in BWS patients. The principal aim of this study was to evaluate the usefulness of KvDMR1 methylation analysis of leukocyte DNA for the diagnosis of BWS. The allelic status of the $11 \mathrm{p} 15$ region and the methylation status of the KCNQ1OT and H19 genes were investigated in leukocyte DNA from 97 patients referred for BWS and classified into two groups according to clinical data: complete BWS (CBWS) ( $n=61)$ and incomplete BWS (IBWS) ( $n=36)$. Fifty-eight (60\%) patients (39/61 CBWS and 19/36 IBWS) displayed abnormal demethylation of KvDMR1. In 11 of the 56 informative cases, demethylation of KvDMR1 was related to $11 \mathrm{p} 15$ uniparental disomy (UPD) (nine CBWS and two IBWS). Thirteen of the 39 patients with normal methylation of KvDMR1 displayed hypermethylation of the $\mathrm{H} 19$ gene. These 13 patients included two siblings with 11p15 trisomy. These results show that analysis of the methylation status of KvDMR1 and the H19 gene in leukocyte DNA is useful in the diagnosis of 11p15-related overgrowth syndromes, resulting in the diagnosis of BWS in more than $70 \%$ of investigated patients. We also evaluated clinical and molecular features as prognostic factors for tumour and showed that mosaicism for 11 p15 UPD and hypermethylation of the $\mathrm{H} 19 \mathrm{gene}$ in blood cells were associated with an increased risk of tumour. European Journal of Human Genetics (2001) 9, 409-418.

Keywords: overgrowth syndrome; Beckwith-Wiedemann syndrome; KCNQ1OT gene; methylation; 11 p15 region; embryonal tumour

*Correspondence: Dr C Gicquel, Laboratoire d'Explorations

Fonctionnelles Endocriniennes, Hôpital Trousseau, 26 Avenue Arnold Netter, 75012 Paris; France.

Tel: +331447364 47; Fax: +331447361 27;

E-mail: christine.gicquel@trs.ap-hop-paris.fr

Received 9 November 2000; revised 5 March 2001; accepted 7 March 2001
Introduction

Beckwith-Wiedemann syndrome (BWS) is a foetal overgrowth disorder with an increased risk of embryonal tumours (most commonly Wilms tumour). ${ }^{1,2}$ This disease is a multigenic disorder caused by dysregulation of the expression of imprinted genes in the $11 \mathrm{p} 15$ chromosomal region. It may involve uniparental disomy (UPD), maternally inherited 
translocations, trisomy with paternal duplication, loss of imprinting (LOI) of the IGF2 gene, a paternally expressed autocrine growth factor, hypermethylation of the H19 gene, a maternally expressed untranslated RNA and mutation in the CDKN1C gene, a maternally expressed cell-cycle regulator (review in ${ }^{3}$ ).

Diagnosis of BWS can be difficult. Clinically, it has to be distinguished from other overgrowth syndromes (OGS) such as Simpson-Golabi-Behmel syndrome and it must also be recognised in its incomplete or related forms such as nonsyndromic IGF2 overgrowth disorder ${ }^{4}$ and isolated hemihyperplasia. ${ }^{5}$ Molecular diagnosis is also difficult, mostly because of the large spectrum of genetic and epigenetic abnormalities. Current molecular tests allow diagnosis of BWS in only one third of patients: rare patients with cytogenetic abnormalities, $20 \%$ of patients with $11 \mathrm{p} 15$ UPD, $8 \%$ of patients with hypermethylation of the H19 gene and $5 \%$ of patients with a mutation in CDKN1C. ${ }^{3,6,7}$

An antisense transcript within intron 10 of the KCNQ1 gene (KCNQ1OT) was recently described as normally expressed from the paternal allele. ${ }^{8-10}$ The function of this imprinted antisense transcript is unknown but its overexpression may affect CDKN1C expression, ${ }^{11}$ thereby contributing to the BWS phenotype. A CpG island (KvDMR1) upstream from the KCNQ1OT gene is specifically methylated in the silent maternal allele. A loss of imprinting of the KCNQ1OT gene has been shown to be frequent in BWS patients, occurring in 31 to $58 \%$ of cases. ${ }^{8-10}$ This loss of imprinting is invariably associated with the loss of maternal allele-specific methylation of KvDMR1. ${ }^{8-10}$

The second difficulty in managing patients with BWS is assessment of tumour risk. The tumour risk for all BWS patients is between 7.5 and $10 \% .{ }^{12-14}$ The tumour screening protocol is currently the same for all patients, regardless of their genetic background. Hemihyperplasia and organomegaly (in particular kidneys) have been shown to be clinical features associated with an increase in the relative risk of cancer. ${ }^{3,14-16}$ It was also suggested that patients with $11 \mathrm{p} 15$ UPD have an increased risk of tumour, ${ }^{17,18}$ but subsequent studies on larger series of patients did not confirm these data. ${ }^{3}$

This work had two aims: (1) to evaluate the usefulness of KvDMR1 methylation analysis of leukocyte DNA, in addition to tests for the presence of 11p15 UPD and methylation analysis of the H19 gene, for the diagnosis of BWS in a large series of 97 patients; (2) to determine whether clinical and/or molecular features are associated with an increased risk of tumour.

\section{Patients and methods \\ Patients}

Ninety-seven patients aged from 1 day to 22 years (53 males and 44 females) were referred to our centre for investigation of Beckwith-Wiedemann syndrome (BWS). Informed consent for access to the collected information was obtained from all patients (or their parents) in accordance with national ethical rules.

Patients were assigned to two groups according to the severity of the phenotype:

- complete form of Beckwith-Wiedemann syndrome (CBWS) ( $n=61)$ : these patients presented at least three of the following four major signs: macrosomia, abdominal wall defect, macroglossia or organomegaly almost always associated with 1 to 4 other characteristic features such as neonatal hypoglycaemia, hemihyperplasia, ear creases and pits, facial naevus flammeus.

- incomplete form of Beckwith-Wiedemann syndrome (IBWS) ( $n=36)$ : these patients presented less than three of the four major signs associated with one to three of the other signs.

The clinical features of the patients are summarised in Table 1.

Tumour occurrence We followed up 97 patients for 566 patient-years. The median follow-up was 4 years (0 to 23.5 years). Twelve patients (11 with CBWS and one with IBWS) developed 14 tumours: Wilms tumour in eight cases, neuroblastoma in two cases, ganglioneuroma in one case, papillary thyroid carcinoma in one case, mammary adenofibroma in one case and bilateral phaeochromocytoma in one case. Data from patients with tumours are summarised in Table 2. Two patients were siblings and half the patients who developed tumours had hemihyperplasia.

The median age at diagnosis of the tumour was 24 months (range: 4 months to 14 years) and most tumours (particularly tumours usually associated with BWS) occurred during the first 5 years of life. After 5 years of life, four events (Table 2: patients 30, 41 and 47) were observed.

In addition to the 12 patients who developed tumours, a patient with CBWS was diagnosed with bilateral enlargement of the adrenal glands before birth. At birth, a high serum level of neurospecific enolase and higher than normal levels of urinary excretion of norepinephrine and dopamine were suggestive of bilateral neuroblastoma. Another patient with IBWS was diagnosed at birth with bilateral nephroblastomatos. Both patients displayed spontaneous favourable evolution and were therefore not considered to be carrying tumours in the prognosis analysis.

Inheritance Nine patients from seven kindreds had at least one relative with definite BWS $(n=8)$ or isolated hemihyperplasia $(n=1)$. The affected relatives were siblings in four families and first cousins in the three remaining families (Figure 1).

Multiple births occurred in five cases: four sets of female twins (two monozygotic and two dizygotic) and one set of mixed twins.

Control population The control population consisted of 25 unrelated and unaffected individuals (seven males and 18 females). 


\section{Methods}

DNA was extracted from leukocytes (all patients) and tissues ( $n=30$, most often tongue tissue obtained from tongue resection for macroglossia and tumours), as previously described. ${ }^{19}$ Parental leukocyte DNA was available for $72 \%$ of the patients.

$11 p 15$ allelic status assessment UPD for chromosome $11 \mathrm{p} 15.5$ was studied by Southern blot analysis using 11p15 polymorphisms as previously described. ${ }^{20}$

In family $\mathrm{F}$, trisomy was investigated by slot-blot densitometry. Briefly, $5 \mu \mathrm{g}$ of DNA was loaded onto Hybond XL membranes (Amersham Pharmacia Biotech, Uppsala, Sweden) and hybridised with an IGF2 or $\beta$-Actin cDNA

Table 1 Clinical features of 97 patients with BeckwithWiedemann syndrome

\begin{tabular}{lll}
\hline & CBWS & IBWS \\
\hline$n$ & 61 & 36 \\
Sex, F/M & $29 / 32$ & $15 / 21$ \\
Macrosomia, n (\%) & $51(83.6)$ & $21(58.3)$ \\
Macroglossia, n (\%) & $60(98.4)$ & $30(83.3)$ \\
Abdominal wall defect, n (\%) & $51(83.6)$ & $14(38.9)$ \\
$\quad$ Diastasis recti, n & 3 & 3 \\
Umbilical hernia, n & 27 & 7 \\
Exomphalos, n & 21 & 4 \\
Organomegaly, n (\%) & $34(55.7)$ & $15(41.7)$ \\
Hemihyperplasia, n (\%) & $25(41)$ & $9(25)$ \\
Hypoglycaemia, n (\%) & $30(49.2)$ & $9(25)$ \\
Ear signs, n (\%) & $32(52.5)$ & $21(58.3)$ \\
Facial nevus, n (\%) & $18(29.5)$ & $12(33.3)$ \\
Tumour, n (\%) & $11(18)$ & $1(2.8)$ \\
\hline
\end{tabular}

CBWS: complete Beckwith-Wiedemann syndrome. IBWS: incomplete Beckwith-Wiedemann syndrome. probe. The autoradiographs were then analysed by densitometry using a GS700 imaging densitometer and the Molecular Analyst data analysis system (Biorad, USA).

Methylation analysis of KvDMR1 and the H19 gene KvDMR1 and H19 gene methylation status was assessed as previously described. ${ }^{8,21}$ Briefly, genomic DNA was digested with BamHI and then with the methylationsensitive enzyme NotI for KvDMR1 analysis and PstI and the methylation-sensitive enzyme SmaI for H19 gene analysis. To ensure complete digestion, a large excess of enzyme was used. Digested samples were subjected to electrophoresis in 0.7 or $1.2 \%$ agarose gels, blotted onto Hybond XL membranes and hybridised with the HLHAY79 KvDMR1 probe corresponding to EST 68627 (ATCC; Manassas, VA, USA) or with a H19 cDNA probe. $^{22}$

The methylation index (MI) of the KCNQ1OT and H19 genes was assessed by densitometry of autoradiographs. The cut-off value for methylation index was $60 \%$.

\section{Statistical methods}

The chi-square test was used to compare qualitative data and correlation tests to compare quantitative data. For prognostic analysis, the event was the first tumour at any site. Tumour-free survival was defined as the time between birth and the time of the event or the last examination if no event occurred. The cut-off date for the analysis was April 302000.

The Kaplan-Meier method was used to estimate tumourfree survival and the results are provided with standard errors (SE). Tumour-free survival was compared between groups of subjects by log rank analysis. The number of events observed in our survey did not allow multivariate analysis. ${ }^{23}$

Table 2 Clinical features and molecular data for patients with tumours

\begin{tabular}{|c|c|c|c|c|c|c|c|c|c|}
\hline \multirow[b]{3}{*}{ Patients } & \multicolumn{5}{|c|}{ Clinical data } & \multicolumn{4}{|c|}{ Molecular data } \\
\hline & & & & & & \multicolumn{3}{|c|}{ Blood cells } & \multirow{2}{*}{$\begin{array}{l}\text { Tumours } \\
11 \text { p } 15 \mathrm{Al} / \% \text { of } \\
\text { disomic cells }\end{array}$} \\
\hline & Sex & Tumour & $\begin{array}{l}\text { Age at } \\
\text { onset }\end{array}$ & Diagnosis & Hemihyperplasia & $\begin{array}{l}11 p 15 \mathrm{Al} / \% \text { of } \\
\text { disomic cells }\end{array}$ & $\begin{array}{l}\text { KvDMR1 } \\
M I\end{array}$ & H19 MI & \\
\hline $82^{a}$ & $\mathrm{~F}$ & ganglioneuroma & $51 \mathrm{~m}$ & CBWS & no & yes/53 & 51 & 77 & NA \\
\hline $83^{a}$ & M & Wilms tumour & $11 \mathrm{~m}$ & CBWS & no & yes $/ 53$ & 48 & 83 & NA \\
\hline 30 & $\mathrm{~F}$ & Wilms tumour & $12 y$ & CBWS & yes & yes $/ 85$ & 82 & 81 & NA \\
\hline 71 & $\mathrm{~F}$ & Wilms tumour & $9 \mathrm{~m}$ & CBWS & yes & yes/64 & 88 & 84 & yes/100 \\
\hline \multirow[t]{2}{*}{55} & $\mathrm{M}$ & neuroblastoma & $4 \mathrm{~m}$ & CBWS & yes & yes/83 & 97 & 92 & NA \\
\hline & & Wilms tumour & $11 \mathrm{~m}$ & & & & & & yes/96 \\
\hline 54 & $\mathrm{~F}$ & Wilms tumour & $24 \mathrm{~m}$ & CBWS & no & no & 52 & 84 & NA \\
\hline 88 & $\mathrm{M}$ & Wilms tumour & $12 \mathrm{~m}$ & CBWS & no & no & 55 & 56 & NA \\
\hline 28 & M & Wilms tumour & $41 \mathrm{~m}$ & CBWS & yes & no & 46 & 71 & $\mathrm{no}^{\mathrm{c}}$ \\
\hline $35^{\mathrm{b}}$ & $\mathrm{M}$ & neuroblastoma & $10 \mathrm{~m}$ & CBWS & no & no & 45 & 54 & NA \\
\hline 41 & $\mathrm{M}$ & thyroid carcinoma & $11 \mathrm{y}$ & CBWS & no & no & 100 & 50 & no $^{\mathrm{d}}$ \\
\hline 47 & $\mathrm{~F}$ & mammary adenoma & $14 y$ & CBWS & yes & yes/56 & 79 & 84 & yes/40 \\
\hline 43 & $\mathrm{M}$ & Wilms tumour & $24 \mathrm{~m}$ & IBWS & yes & no & 59 & 86 & no \\
\hline
\end{tabular}

CBWS: complete BWS, IBWS: incomplete BWS; 11 p15 Al: 11 p15 allelic imbalance; MI: methylation index; NA: not available; y: years; m: months. ${ }^{a}$ Patients from the same kindred. ${ }^{b}$ Patient with CDKN1C mutation. ${ }^{a, b}$ Familial cases (families D and F). ${ }^{C}$ Hypermethylation of the H19 gene and loss of imprinting of the IGF2 gene in peritumoural and tumour tissues. Demethylation of KvDMR1 in tumour tissue. ${ }^{\text {e }}$ Hypermethylation of the $\mathrm{H} 19$ gene in peritumoural and tumour tissues. d,e Patients non informative for exonic polymorphisms of the IGF2 gene. 

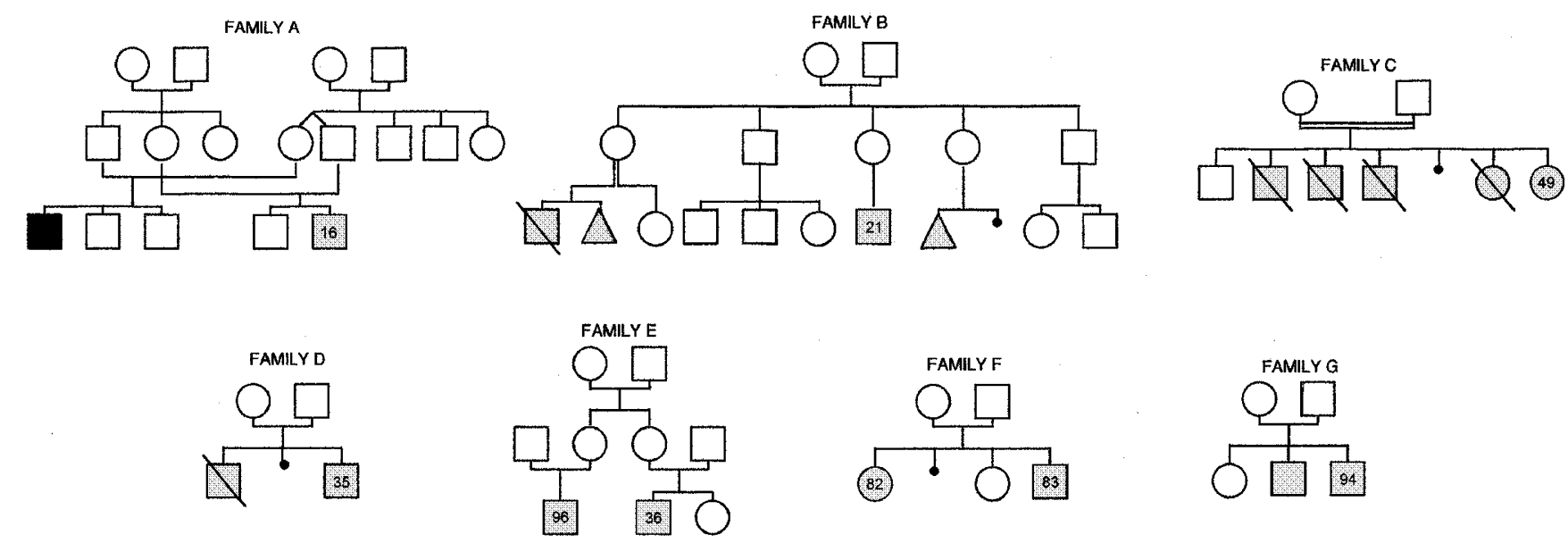

Figure 1 Pedigrees of seven kindreds with familial BWS. Patients numbered 16, 21, 35, 36, 49, 82, 83 and 94 had CBWS and the patient numbered 96 had IBWS. The black square represents a patient with isolated hemihyperplasia.

\section{Results}

KvDMR1 and H19 methylation analysis in blood samples KVDMR1 methylation analysis Southern blot analysis of leukocyte DNA from 25 control subjects showed two bands (4.2 and $6 \mathrm{~kb}$ ) of equal intensity (Figure 2A) after digestion with BamHI and NotI, indicating that the DNA was normally methylated on the maternal chromosome. KvDMR1 methylation index (MI) was normal, at between 45 and $56 \%$ (mean $\pm \mathrm{SD}=51.6 \pm 2.5 \%$ ) (Figure $2 \mathrm{~B}$ ).

Fifty-eight of the 97 (60\%) BWS patients (39 CBWS and 19 IBWS) (Figures 2A,B and 3) exhibited hypomethylation of the allele that is normally methylated, the MI for KvDMR1 being between 61 and 100\%. Fifty-six (96.6\%) patients were informative for at least one 11p15.5 polymorphism and 11 (nine CBWS and two IBWS) displayed allelic imbalance in favour of partial UPD (mosaicism). For these 11 patients, KvDMR1 MI was correlated with the level of mosaicism ( $r=0.77 ; P<0.0001$ ) (Figure 2C). The other 45 informative patients had isolated demethylation of KvDMR1.

H19 methylation analysis Southern blot analysis of leukocyte DNA from 25 control subjects showed two bands (1.8 and $1 \mathrm{~kb}$ ) of equal intensity (Figures 2D) after digestion with PstI and SmaI, indicating that the DNA was normally unmethylated on the maternal chromosome. The MI for H19 was between 48 and $60 \%$ (mean $\pm \mathrm{SD}=53.3 \pm 3.1 \%$ ) (Figure $2 \mathrm{E}$ ).

Twenty-six patients showed hypermethylation of the maternal allele (normally unmethylated), the MI for H19 being between 64 and 93\% (Figures 2D,E and 3). Eleven of the 24 informative patients had allelic imbalance in favour of partial UPD and the MI for H19 was correlated with the level of mosaicism $(r=0.7 ; P=0.01)$ (Figure $2 \mathrm{~F}$ ). Two other of the 25 informative patients were siblings with $11 \mathrm{p} 15$ trisomy. The 11 remaining informative patients had isolated hypermethylation of the H19 gene.
No patients other than those with partial UPD exhibited abnormal methylation of both the H19 and KCNQ1OT genes.

\section{Molecular abnormalities in other tissues}

We carried out tests for the presence of 11p15 UPD and KvDMR1 methylation analysis using 30 tissue samples from 24 patients, mostly tongue tissues $(n=17)$ and tumours $(n=6)$. All analyses were concordant and, if 11p15 UPD was found in leukocyte DNA, it was also found in the other tissues analysed. If the MI for KvDMR1 was abnormal in leukocytes, it was also abnormal in other tissues. However, the level of 11p15 mosaicism and the MI for KvDMR1 did differ in some cases between different tissues from the same patient (Figure 4).

\section{Genotype-phenotype correlations}

We compared the frequency of exomphalos in patients with isolated demethylation of KvDMR1 to that in patients with other molecular abnormalities (isolated hypermethylation of the H19 gene or 11p15 UPD). Of 45 patients with isolated demethylation of KvDMR1, 18 (40\%) had exomphalos. This frequency was significantly greater than that for patients with 11p15 UPD or isolated hypermethylation of the H19 gene, for whom exomphalos was detected in only two of 26 $(8 \%)$ cases (Chi square: $P<0.0001)$.

\section{Familial studies}

Four familial cases (from families A, B and F) exhibited abnormalities of the $11 \mathrm{p} 15$ region. In family $\mathrm{A}$, the proband (patient 16) exhibited complete demethylation of KvDMR1, although a first cousin with isolated hemihyperplasia had normal methylation of KvDMR1 (Figure 5). In family B, the four affected subjects were the offspring of three normal sisters. Analysis of one affected subject (patient 21) showed complete demethylation of KvDMR1, although the mother 
(an obligate carrier) showed no abnormality (Figure 5). In family $\mathrm{F}$, an allelic imbalance at the 11p15 locus was shown by Southern blot analysis in two siblings who developed tumours (Table 2, patients 82 and 83). Cytogenetic analyses were normal but FISH analyses could not be carried out. Densitometric analysis of Southern and slot blots hybridised with the IGF2 probe and the $\beta$-Actin probe as a control (locus $7 p)$ showed that the ratio of IGF2 signal to $\beta$-Actin was higher in samples from the two siblings and their father. These data are consistent with paternally inherited trisomy (Figure 5).

Two pairs of female monozygotic twins have been investigated. In both cases, one twin showed typical BWS whereas the other did not. One pair of twins had a 47, XXX karyotype. Analysis of the 11 p15 region showed the same abnormality (almost complete demethylation of KvDMR1) in both BWS twins and in normal twins (Figure 6).

\section{Prognostic study}

The overall tumour-free survival rate at 5 years was $86 \%$ (SE 4.4\%) (Figure 7A). As assessed by univariate analysis, severity of the phenotype was the only clinical sign associated with a tumour risk ( $P=0.05$; hazard ratio: 5.9 ): $18 \%$ of CBWS patients and $2.8 \%$ of IBWS patients developed tumours. Hemihyperplasia and organomegaly were not significantly associated with tumour risk, even though the frequency of tumours in patients with hemihyperplasia or organomegaly was twice that in patients without these features (Table 3). A positive correlation was observed between hemihyperplasia and 11 p15 UPD. Ten of 32 (31.25\%) patients with hemihyperplasia, informative for $11 \mathrm{p} 15$ markers, exhibited 11p15 UPD whereas only three of $63(4.8 \%)$ patients without hemihyperplasia had 11p15 UPD (Chi square=0.0004).

We found that 11p15 allelic imbalance in blood cells was strongly associated with tumour risk $(P<0.0001$, hazard ratio 8.1): six of the $13(46.2 \%)$ patients with $11 \mathrm{p} 15$ allelic imbalance (UPD in 11 cases and partial trisomy in two cases) developed tumours whereas tumours occurred in only six of the patients without 11p15 allelic imbalance (7.3\%) (Tables 2 and 3). The prognostic value was similar when we considered independently the methylation status of the H19 gene. The prognostic value of these factors is illustrated by KaplanMeier curves of tumour-free survival (Figure 7B-D).

\section{Discussion}

BWS is genetically complex and heterogeneous. Molecular diagnosis of BWS is currently possible in only one third of patients and the first aim of the study was to assess the methylation status of KvDMR1 in blood samples as a diagnostic test for BWS. KvDMR1 methylation analysis in leukocyte DNA alone identified BWS in $60 \%$ of all patients (64\% of patients with a severe form and $53 \%$ of patients with incomplete forms of BWS). Demethylation of KvDMR1 was isolated in 45 cases and was related to mosaicism for UPD in the 11 informative cases. Analysis of the methylation status of the H19 gene identified 13 other BWS patients with hypermethylation of the H19 gene. KCNQ1OT and H19 gene analysis is thus useful in routine investigation, and led to the diagnosis of 11p15-related overgrowth syndrome in 71 of 97 (73.2\%) patients referred for BWS. One advantage of such methylation analyses is that they do not require informativity for a marker and are thus available for all patients. To date, in all cases in which demethylation of the KCNQ1OT gene has been reported in BWS patients, it has been described as complete. ${ }^{8-10}$ In this study, about $70 \%$ of the patients with isolated demethylation of the KCNQ1OT gene displayed complete or almost complete demethylation (KvDMR1 MI $>90 \%$ ), but about one third showed partial demethylation, suggesting that this abnormality can occur with mosaicism. These results are supported by analyses of other pathological tissues, showing patterns of demethylation different from that in blood cells. For example, KvDMR1 was incompletely demethylated in tongue tissues from patients with complete demethylation in blood cells. However, if it was demethylated in blood cells, KvDMR1 was at least partially demethylated in other studied tissues, suggesting that the analysis of blood samples is sufficient for diagnosis of BWS. We also observed that demethylation of the KCNQ1OT gene was never associated with abnormal methylation of the H19 gene except in patients with 11p15 UPD, suggesting that at least two imprinting centres exist on 11p15.5. ${ }^{7,24}$ We also observed that exomphalos was associated with demethylation of the KCNQ1OT gene and these data are consistent with the recent study by Engel et al. ${ }^{24}$

Mosaicism for 11p15 UPD was more frequent in complete forms than in incomplete forms of BWS, suggesting that both the tissue distribution of mosaicism and the proportion of mosaic cells may account for the various phenotypes, as recently shown by Itoh et al. ${ }^{25}$ In addition, 11p15 UPD was significantly more frequent in patients with hemihyperplasia than in patients without hemihyperplasia.

Probands from three of the seven affected families displayed abnormalities of the 11 p15 region. In one family, we showed paternally inherited 11p15 trisomy in two siblings with normal results for karyotype analysis. These data require confirmation by FISH analysis. Surprisingly, these two patients developed tumours despite the theorically very low risk of tumour in trisomic cases. In the two other families, probands showed isolated demethylation of KvDMR1. In one of these families, this abnormality was not found in a first cousin with isolated hemihyperplasia. Furthermore, when studying a series of patients with isolated hemihyperplasia we did not show epigenetic abnormalities (such as isolated demethylation of KvDMR1 or isolated hypermethylation of the H19 gene) but only 11p15 UPD (personal data). These data show that demethylation of KvDMR1 can occur in familial BWS.

Twin pairs are invariably discordant for BWS, although the second twin may occasionally show minor features. An excess of female monozygotic twin pairs has been observed 
A

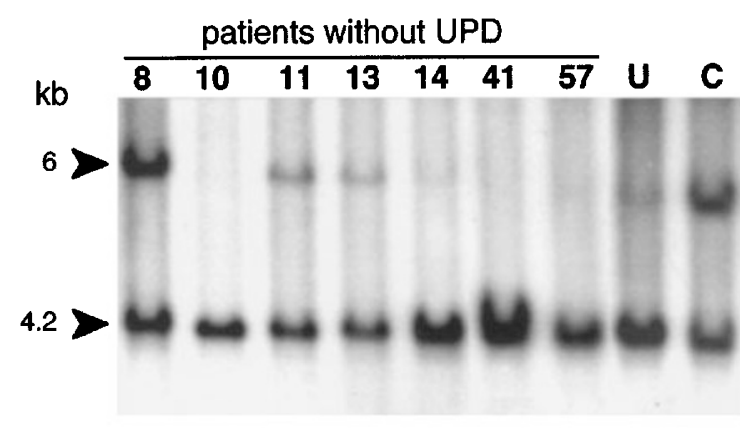

B

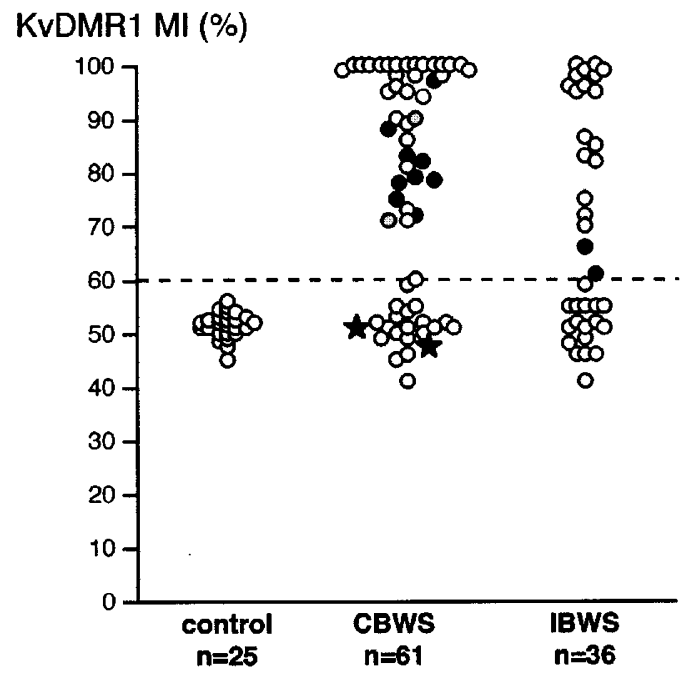

C

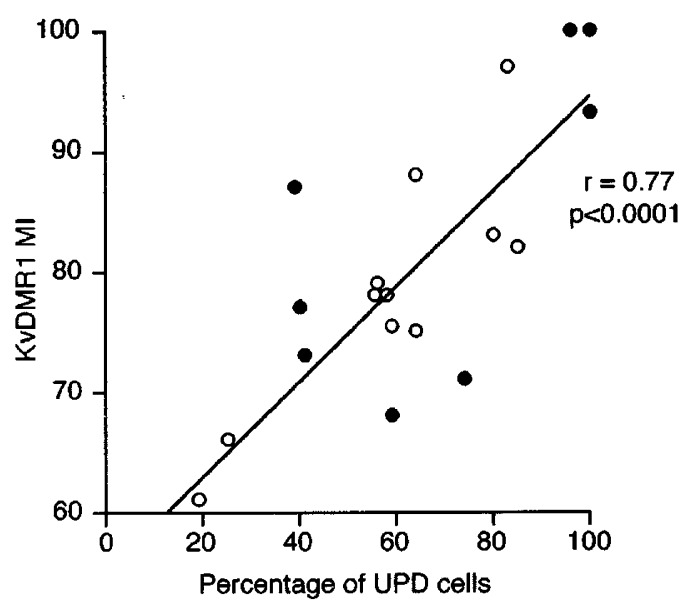

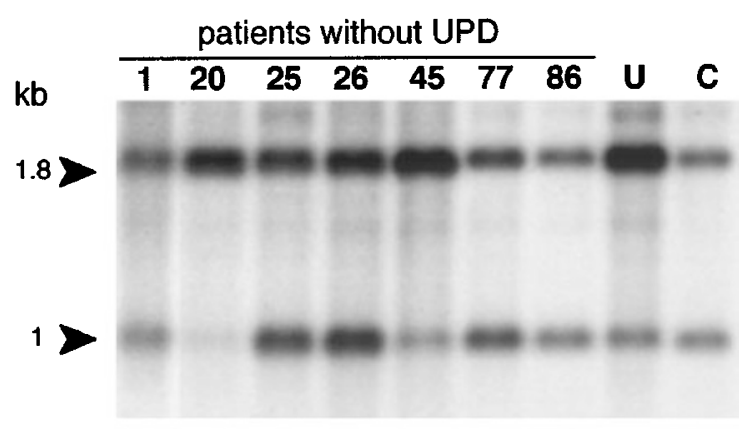

E

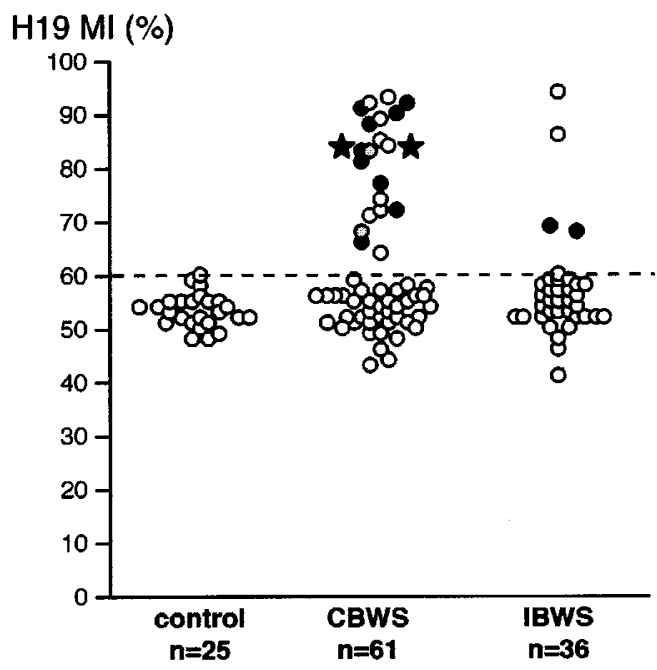

F

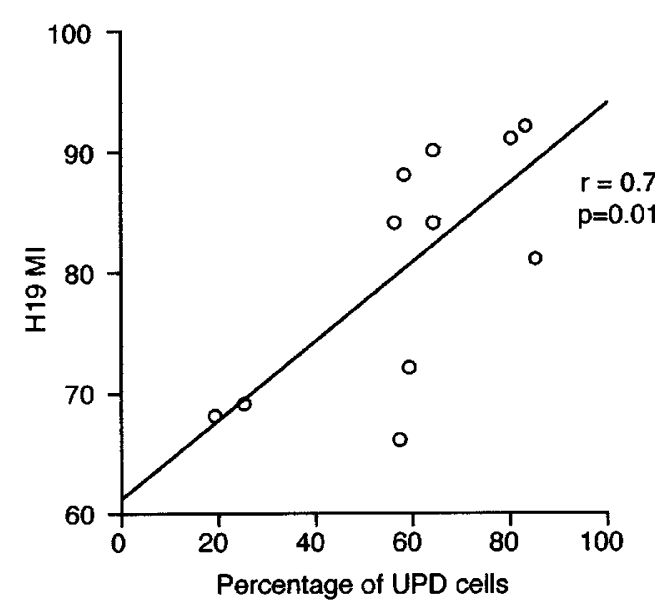

Figure 2 Methylation analysis of KvDMR1 and $\mathrm{H} 19$ gene in BWS patients and normal subjects. A, KvDMR1 methylation was assessed by digestion with BamHI and Notl. The $6 \mathrm{~kb} \mathrm{BamHI}$ fragment is cut with Notl, resulting in a $4.2 \mathrm{~kb}$ fragment. The KvDMR1 methylation index was determined by scanning autoradiographs and dividing the intensity of the $4.2 \mathrm{~kb}$ band by the sum of the intensities of the 4.2 and $6 \mathrm{~kb}$ bands. $\mathrm{U}$ is a blood sample from a confirmed UPD BWS case; $\mathrm{C}$ is a control blood sample. B, Methylation index of KvDMR1 in the 
among twin pairs with normal chromosomes. ${ }^{26-28}$ It has been suggested that the excess of female monozygotic twin pairs may be related to the process of $X$ chromosome inactivation. ${ }^{29}$ In this study we investigated two monozygotic female twin pairs, one of which had an abnormal 47,XXX karyotype. In analysis of the 11 p15 region, we showed that the BWS and unaffected twins of each twin pair exhibited the same epigenetic abnormalities (ie demethylation of KvDMR1) in blood cells. $X$ chromosome inactivation determined at the M27 $\beta$ locus, ${ }^{19}$ in DNA from peripheral blood cells, was similar in BWS patients and their unaffected twins (data not shown). These data raise questions as to the tissue distribution of epimutated cells in the two twins.

The second aim of the study was to assess the prognostic value of various clinical and molecular factors. Although the frequency of hemihyperplasia was higher in patients with tumours than in patients without tumours, we found that hemihyperplasia had no significant prognostic value $(P=0.21)$. This result conflicts with that of deBaun et al, for a large series of 183 patients. ${ }^{14}$ Phenotype severity was the only clinical sign with significant prognostic value for the appearance of tumours $(P=0.05)$. Moreover, 11p15 UPD and abnormal methylation of the $\mathrm{H} 19$ gene in blood cells were both of prognostic value. Both abnormalities are responsible for reduced H19 expression. An association between reduced H19 expression in BWS and susceptibility to Wilms tumour has been suggested 7,9,24,30 and our data are consistent with this hypothesis. However, due to the small sample size and the low frequency of events (tumours in 12 patients of our study and three patients of Engel's study), these results require confirmation in larger series of patients. Nevertheless, they suggest that patients exhibiting these abnormalities in blood cells should be investigated in more detail.

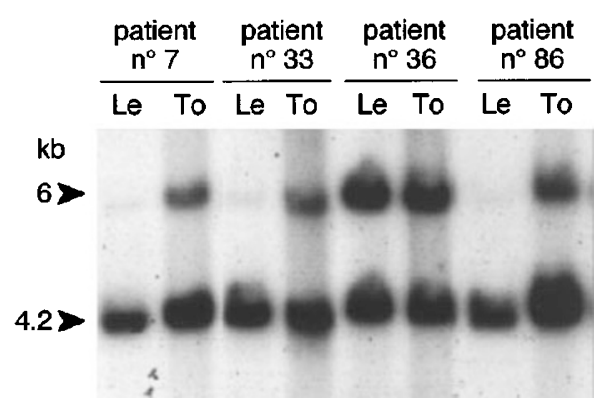

Figure 4 Methylation analysis of KvDMR1 in leukocytes (Le) and tongue tissues (To) from four BWS patients without 11p15 UPD.

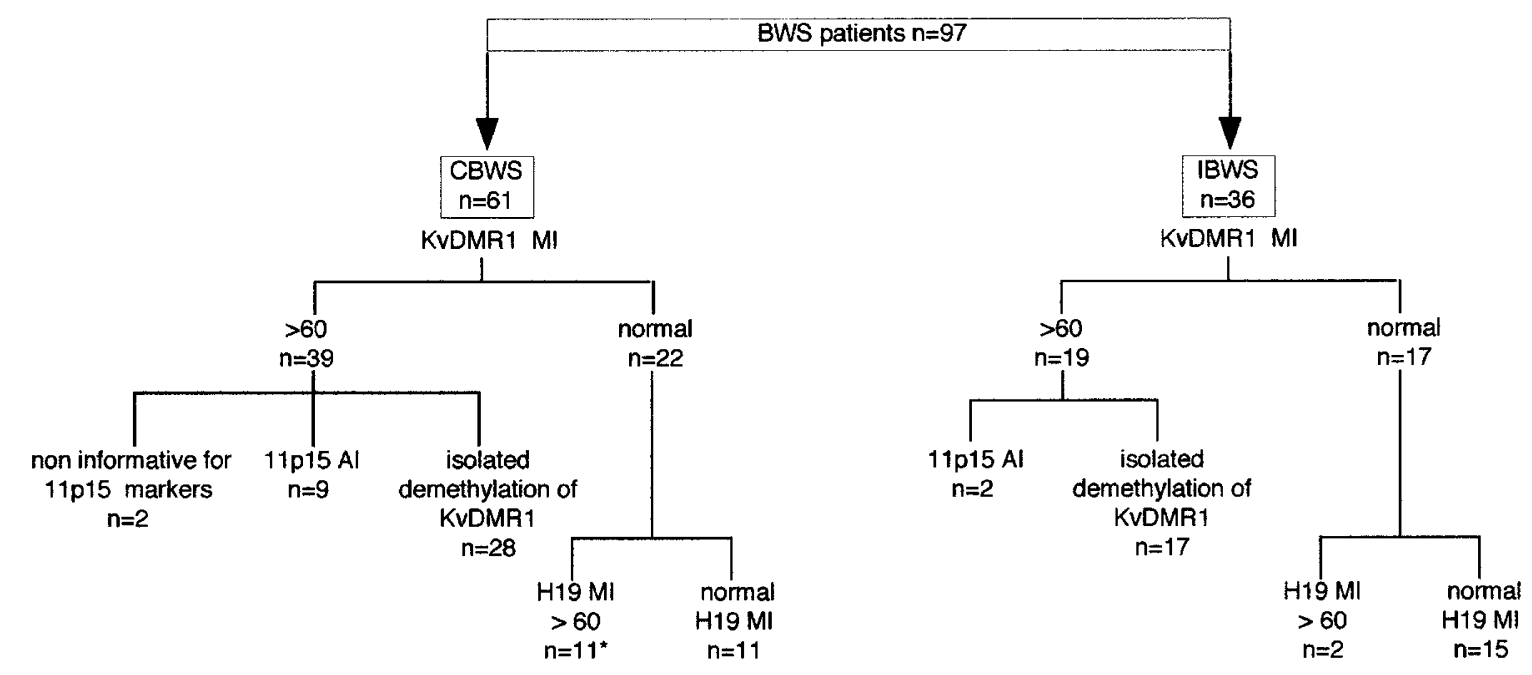

Figure 3 Genotype of patients investigated for BWS. * two of these 11 patients are trisomic patients (patients 82 and 83 ).

three study groups: control subjects ( $n=25)$; complete Wiedemann-Beckwith syndrome (CBWS) ( $n=61)$ and incomplete Wiedemann Beckwith syndrome (IBWS) ( $n=36)$. $\bigcirc$ non UPD patients; 1 UPD patients; 0 non informative patients; * trisomic patients (patients 82 and 83). C, KvDMR1 methylation index (MI) plotted against percentage of UPD cells in blood ( $\bigcirc)$ and tissue samples (O). D, H19 methylation was assessed by digestion with Pstl and Smal. The $1.8 \mathrm{~kb}$ Pstl fragment is cut with Smal, resulting in a $1 \mathrm{~kb}$ fragment. The $\mathrm{H} 19$ methylation index was determined by scanning autoradiographs and dividing the intensity of the $1.8 \mathrm{~kb}$ band by the sum of the intensities of the $1.8 \mathrm{~kb}$ and $1 \mathrm{~kb}$ bands. $U$ is a blood sample from a confirmed UPD BWS case; $C$ is a control blood sample. E, Methylation index of the $\mathrm{H} 19$ gene in the three study groups: control subjects ( $n=25)$; complete Beckwith - Wiedemann syndrome (CBWS) ( $n=61$ ) and incomplete Beckwith -Wiedemann syndrome (IBWS) $(n=36)$. $\bigcirc$ non UPD patients; $\bigcirc$ UPD patients; $\bigcirc$ non informative patients; * trisomic patients (patients 82 and 83 ). F, H19 methylation index (MI) plotted against percentage of UPD cells in blood samples. 

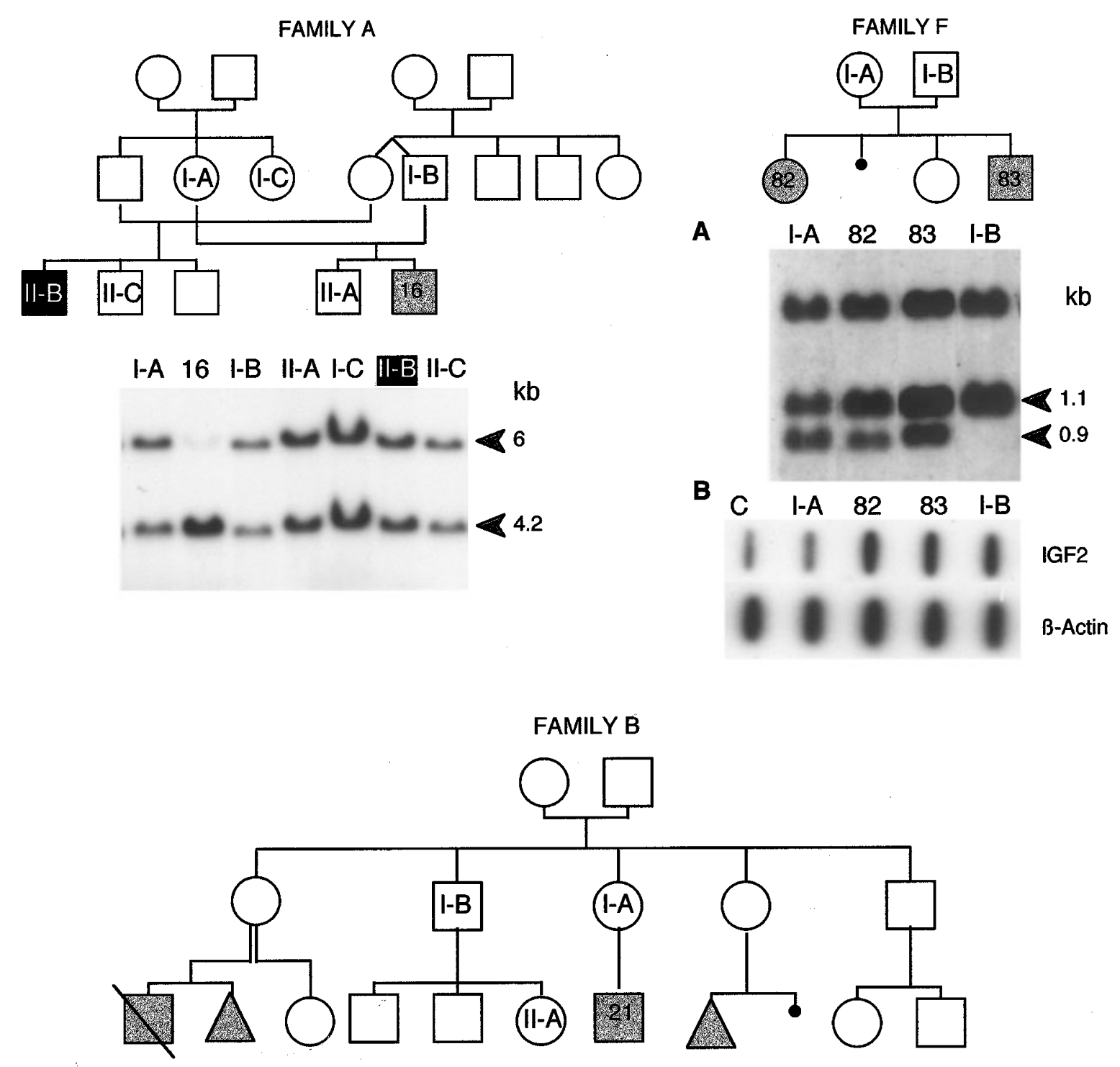

I-A $21 \quad$ II-A $\quad$ I-B

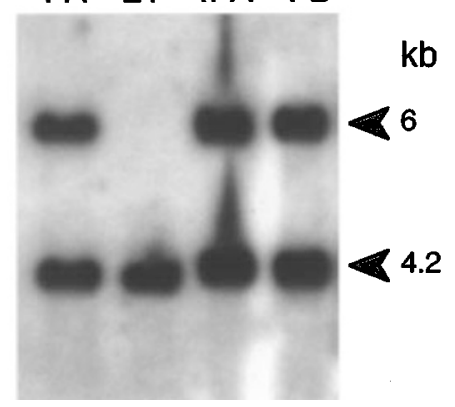

Figure 5 Methylation analysis of KvDMR1 in leukocyte DNA from patients and relatives from families A and B. Analysis of leukocyte DNA in patients and relatives from family F. A, Southern blot analysis: DNA was digested with Avall and hybridised with an IGF2 cDNA probe. B, Slot blot analysis; $C$ is a control blood sample. 
Analyses of the KCNQ1OT and H19 genes were normal for 26 patients (26.8\%). Sequencing of the CDKN1C gene had been undertaken in 10 of these patients (five sporadic forms and the five patients from families C, D, E and G). No abnormality was found in sporadic cases. ${ }^{31}$ Germline CDKN1C mutations were found in families D (patient 35) and $\mathrm{G}$ (patient 94) and both patients had exomphalos. Other unknown 11p15 abnormalities may account for the other
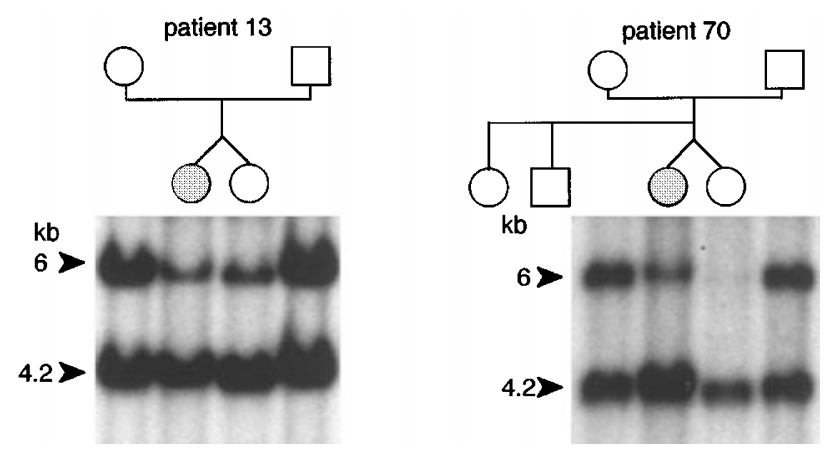

Figure 6 Methylation analysis of KvDMR1 in leukocytes from two monozygotic twins and their parents. Patient 13 and her twin had a 47,XXX karyotype.
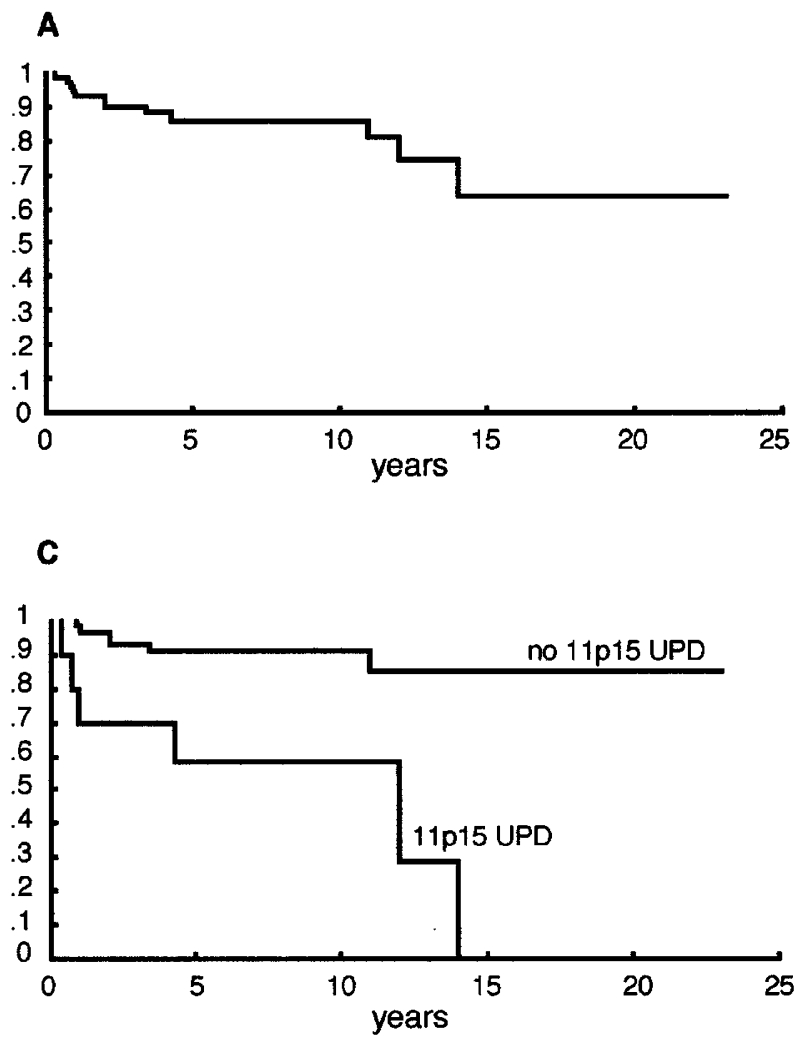

cases. Alternatively, various mechanisms may induce an overgrowth syndrome by inducing the activity of growth factors such as IGF2. Several transgenic mice models have provided evidence for this by showing an increase in

Table 3 Univariate analysis comparing tumour-free survival with clinical and molecular features

\begin{tabular}{|c|c|c|c|c|}
\hline & & $\begin{array}{l}\text { Tumour } \\
\text { n (\%) }\end{array}$ & $\begin{array}{l}\mathrm{P} \\
\text { value }\end{array}$ & $\begin{array}{l}\text { Hazard } \\
\text { ratio }\end{array}$ \\
\hline Phenotype & $\begin{array}{l}\text { CBWS } \\
\text { IBWS }\end{array}$ & $\begin{array}{l}11 / 61(18) \\
1 / 36(2.8)\end{array}$ & 0.05 & 5.9 \\
\hline Exomphalos & $\begin{array}{l}\text { Yes } \\
\text { No }\end{array}$ & $\begin{array}{l}3 / 25(12) \\
9 / 72(12.5)\end{array}$ & 0.86 & 1.1 \\
\hline Organomegaly & $\begin{array}{l}\text { Yes } \\
\text { No }\end{array}$ & $\begin{array}{l}9 / 49(18.4) \\
3 / 41(7.3)\end{array}$ & 0.18 & 2.35 \\
\hline Hemihyperplasia & $\begin{array}{l}\text { Yes } \\
\text { No }\end{array}$ & $\begin{array}{l}6 / 34(17.6) \\
6 / 60(10)\end{array}$ & 0.21 & 2 \\
\hline 11p15 allelic imbalance & $\begin{array}{l}\text { Yes } \\
\text { No }\end{array}$ & $\begin{array}{l}6 / 13(46.2) \\
6 / 82(7.3)\end{array}$ & $<0.0001$ & 8.1 \\
\hline Abnormal KvDMR1 MI & $\begin{array}{l}\text { Yes } \\
\text { No }\end{array}$ & $\begin{array}{l}7 / 60(11.7) \\
5 / 37(13.5)\end{array}$ & 0.12 & 0.41 \\
\hline Abnormal H19 MI & $\begin{array}{l}\text { Yes } \\
\text { No }\end{array}$ & $\begin{array}{l}9 / 26(34.6) \\
3 / 71(4.2)\end{array}$ & $<0.0001$ & 10 \\
\hline
\end{tabular}

CBWS: complete Beckwith-Wiedemann syndrome. IBWS: incomplete Beckwith-Wiedemann syndrome.

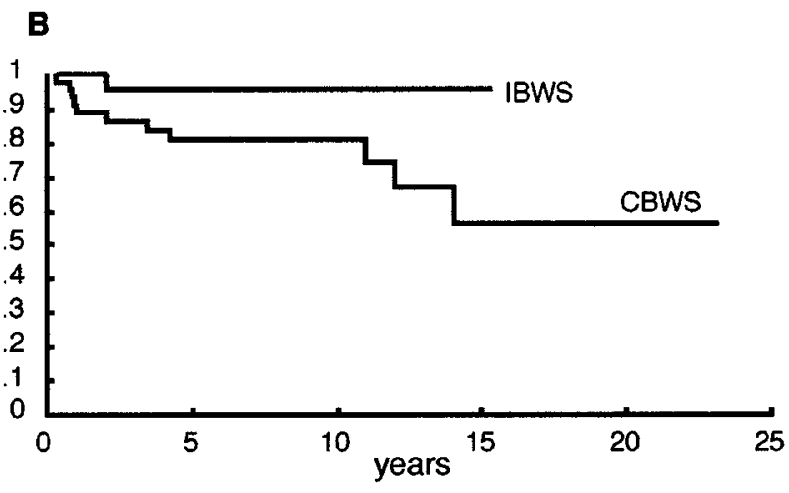

\section{D}

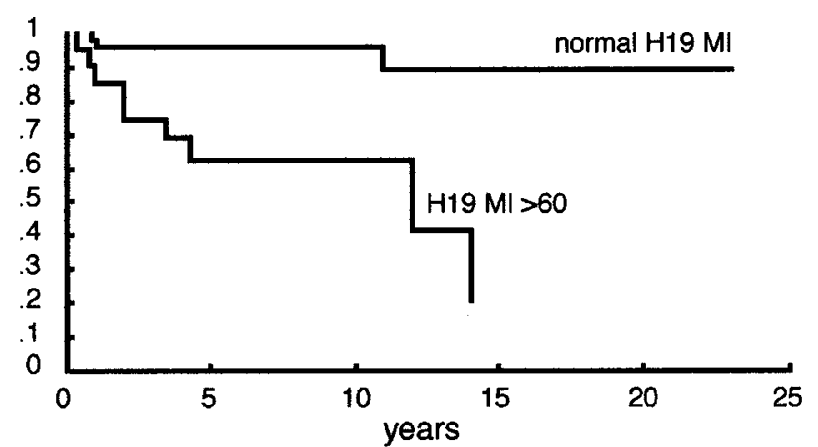

Figure 7 A, Global Kaplan-Meier tumour-free survival curve in 97 patients with BWS. B, Kaplan-Meier tumour-free survival curves according to phenotype (complete BWS vs incomplete BWS). C, Presence of $11 \mathrm{p} 15$ allelic imbalance in blood cells. D Methylation index of the $\mathrm{H} 19$ gene (normal MI vs abnormal MI). 
bioactive IGF2 levels resulting from the inhibition of IGF receptor type 2 (IGF2R) ${ }^{32}$ or Glypican $3,{ }^{33}$ two factors known to bind and to downregulate IGF2, making it less available for the type 1 IGF-receptor. Further studies of 11 p15 genes and IGF2-related regulators in overgrowth syndromes should be carried out to determine the relationship between genotype and phenotype and to elucidate functional mechanisms.

\section{Acknowledgements}

This work was supported by Assistance Publique-Hopitaux de Paris: Contrat de Recherche Clinique $n^{\circ}$ 97133, by the University Paris VI, Faculté Saint-Antoine (UPRESS EA 1531) and by INSERM (U515). We thank Drs Battin, Baudon, Baumann, Bensman, Blanchet, Bonneau, Brugières, Cabrol, Chatelain, Chaussain, Coutant, David, Dendale, Estéva, Faivre Gourmelen, Guillot, Heimann, Holder-Espinasse, Houang, Lacombe, Landmann-Parker, Lasfargues, Léger, Leheup, Leverger, Limal, Lyonnet Mayer, Moncla, Montagnon, Nicolino, Nivelon, Polak, Puel, Rappaport, Raux-Demay, Rocchicioli, Safar, Sarda, Sariban, Schlumberger, Tauber, Teinturier and Wagner for their help in the assessment of patients.

\section{References}

1 Pettenati M, Haines J, Higgins R, Wappner R, Palmer C, Weaver D: Wiedemann-Beckwith syndrome: presentation of clinical and cytogenetic data on 22 new cases and review of the literature. Hum Genet 1986; 74: 143-154.

2 Elliot M, Maher E: Beckwith-Wiedemann syndrome. I Med Genet 1994; 31: 560-564.

3 Li M, Squire J, Weksberg R: Molecular genetics of WiedemannBeckwith syndrome. Am J Med Genet 1998; 79: 253 - 259.

4 Morison I, Becroft D, Taniguchi T, Woods C, Reeve A: Somatic overgrowth associated with overexpression of insulin-like growth factor II. Nat Genet 1996; 2: 311-316.

5 Hoyme HE, Seaver LH, Jones KL, Procopio F, Crooks W, Feingold M: Isolated hemihyperplasia (hemihypertrophy): report of a prospective multicenter study of the incidence of neoplasia and review. Am J Med Genet 1998; 79: 274-278.

6 Morison IM, Reeve AE: Insulin-like growth factor 2 and overgrowth: molecular biology and clinical implications. Mol Med Today 1998; 4: 110-115.

7 Maher ER, Reik W: Beckwith - Wiedemann syndrome: imprinting in clusters revisited. J Clin Invest 2000; 105: 247 - 252.

8 Smilinich N, Day C, Fitzpatrick G et al: A maternally methylated CpG island in KvLQT1 is associated with an antisense paternal transcript and loss of imprinting in Beckwith-Wiedemann syndrome. Proc Natl Acad Sci USA 1999; 96: 8064-8069.

9 Lee $M$, Debaun $M$, Mitsuya $K$ et al: Loss of imprinting of a paternally expressed transcript, with antisense orientation to KvLQT1, occurs frequently in Beckwith - Wiedemann syndrome and is independent of insuline-like growth factor II imprinting. Proc Natl Acad Sci USA 1999; 96: 5203-5208.

10 Mitsuya K, Meguro M, Lee M et al: LIT1, an imprinted antisense RNA in the human KvLQT1 locus identified by screening for differentially expressed transcripts using monochromosomal hybrids. Hum Mol Genet 1999; 8: 1209-1217.

11 Horike S, Mitsuya K, Meguro M et al: Targeted disruption of the human LIT1 locus defines a putative imprinting control element playing an essential role in Beckwith-Wiedemann syndrome. Hum Mol Genet 2000; 9: 2075-2083.

12 Sotelo-Avila C, Gonzalez-Crussi F, Fowler J: Complete and incomplete forms of Beckwith-Wiedemann syndrome: their oncogenic potential. J Pediatr 1980; 96: 47-50.
13 Wiedemann H: Tumors and hemihypertrophy associated with Wiedemann-Beckwith syndrome. Eur J Pediatr 1983; 141: 129.

14 DeBaun MR, Tucker MA: Risk of cancer during the first four years of life in children from the Beckwith-Wiedemann syndrome registry. J Pediatr 1998; 132: 398-400.

15 Schneid H, Vazquez MP, Vacher C, Gourmelen M, Cabrol S, Le Bouc Y: The Beckwith-Wiedemann syndrome phenotype and the risk of cancer. Med Pediatr Oncol 1997; 28: 411-415.

16 DeBaun MR, Siegel MJ, Choyke PL: Nephromegaly in infancy and early childhood: a risk factor for Wilms tumor in Beckwith Wiedemann syndrome. J Pediatr 1998; 132: 401-404.

17 Henry I, Puech A, Riesewijk A et al: Somatic mosaicism for partial paternal isodisomy in Wiedemann - Beckwith syndrome: a post-fertilization event. Eur J Hum Genet 1993; 1: 19-29.

18 Schneid H, Seurin D, Vazquez M, Gourmelen M, Cabrol S, Le Bouc Y: Parental allele specific methylation of the human insulin-like growth factor II gene and Beckwith - Wiedemann syndrome. J Med Genet 1993; 30: 353-362.

19 Gicquel C, Le Bouc Y, Luton J, Girard F, Bertagna X: Monoclonality of corticotroph macroadenomas in Cushing's disease. J Clin Endocrinol Metab 1992; 75: 472-475.

20 Gicquel C, Bertagna X, Schneid H et al: Rearrangements at 11 p15 locus and overexpression of Insulin like growth factor-II gene in sporadic adrenocortical tumors. J Clin Endocrinol Metab 1994; 78: $1444-1453$.

21 Reik W, Brown KW, Slatter RE, Sartori P, Elliott M, Maher ER: Allelic methylation of H19 and IGF2 in the BeckwithWiedemann syndrome. Hum Mol Genet 1994; 3: 1297-1301.

22 Brannan C, Dees E, Ingram R, Tilghman S: The product of the H19 gene may function as a RNA. Mol Cell Biol 1990; 10: 28-36.

23 Collet D: Modelling survival data in medical research. In: Text in statistical science. Chapman and Hall, London, 1994

24 Engel J, Smallwood A, Harper A et al: Epigenotype-phenotype correlations in Beckwith-Wiedemann syndrome. J Med Genet 2000; 37: 921 - 926.

25 Itoh N, Becroft DM, Reeve AE, Morison IM: Proportion of cells with paternal $11 \mathrm{p} 15$ uniparental disomy correlates with organ enlargement in Wiedemann-Beckwith syndrome. Am J Med Genet 2000; 92: 111-116.

26 Clayton-Smith J, Read AP, Donnai D: Monozygotic twinning and Wiedemann-Beckwith syndrome. Am J Med Genet 1992; 42: $633-637$.

27 Franceschini P, Guala A, Vardeu MP, Franceschini D: Monozygotic twinning and Wiedemann-Beckwith syndrome. Am Med Genet 1993; 46: 353-354.

28 Leonard NJ, Bernier FP, Rudd N et al: Two pairs of male monozygotic twins discordant for Wiedemann-Beckwith syndrome. Am J Med Genet 1996; 61: 253-257.

29 Orstavik RE, Tommerup N, Eiklid K, Orstavik KH: Non-random $\mathrm{X}$ chromosome inactivation in an affected twin in a monozygotic twin pair discordant for Wiedemann-Beckwith syndrome. Am J Med Genet 1995; 56: 210-214.

30 Tycko B: Epigenetic gene silencing in cancer. J Clin Invest 2000; 105: $401-407$.

31 Gaston V, Le Bouc Y, Soupre V, Vazquez M, Gicquel C: Assessment of p57KIP2 gene mutation in Wiedemann-Beckwith syndrome. Horm Res 2000; 54: 1-5.

32 Eggenschwiler J, Ludwig T, Fisher P, Leighton P, Tilghman M, Efstratiadis A: Mouse mutant embryos overexpressing IGF-II exhibit phenotypic features of the Beckwith-Wiedemann and Simpson-Golabi-Behmel syndromes. Genes Dev 1997; 11: 3128 3142 .

33 Cano-Gauci D, Song H, Yang H et al: Glypican-3-deficient mice exhibit developmental overgrowth and some of the abnormalities typical of Simpson-Golabi-Behmel syndrome. J Cell Biol 1999; 146: $255-264$. 